\title{
REPERTORIUM VAN TIJDSCHRIFTLITERATUUR OP HET GEBIED VAN ACCOUNTANCY EN BEDRIJFSHUISHOUDKUNDE
}

Verschïnt maandelijks, behalve in augustus. Samerigesteld door de Stichting voor Economisch Onderzoek der Universiteit van Amsterdam.

\section{A. ACCOUNTANCY}

\section{ACCOUNTANTSBEROEP}

\section{De ondertekening van de accountantsverklaring met een persoonlijke naam of een ge- meenschappelijke naam}

Rietschoten, Prof. A. M. van - In het geval van uitoefening van het accountantsberoep onder gemeenschappelijke naam kent men in Nederland voor de ondertekening van de verklaring het tekenen met alleen de maatschapsnaam naast het tekenen met de persoonlijke naam van de vennoot die de verklaring geeft onder de maatschapsnaam. Deze laatste wijze van ondertekening komt meer voor dan de eerste en is zelfs regel als de gemeenschappelijke naam een on persoonlijke naam is. Het bezwaar van het gebruiken van een onpersoonlijke naam is dat de naam beperkt blijft tot een algemene aanduiding van het beoefende beroep en daarmede de neiging heeft ongewild meer pretentieus te worden dan in het beroep past.

Aan het gebruik van de persoonlijke gemeenschappelijke naam ook na uittreding van de vennoten die de samenwerking hebben gegrondvest zijn voordelen verbonden met betrekking tot het vertrouwen en het gezag dat in het maatschappelijk verkeer van de naam uitgaat. De doelmatigheid van het gebruik van de gemeenschappelijke naam vormt de grond voor de voorkeur voor ondertekening uitsluitend met de maatschapsnaam. Deze wijze van ondertekening brengt de voor het gebruik van de gemeenschappelijke naam vereiste vaktechnische eenheid het best naar buiten. Het vermijdt het in gedrang komen van de vaktechnische eenheid door verschillen in anciënniteit der vennoten en voorkomt dat bij volgtijdelijk wisselen van vennoten bij de lezer van de verklaring vragen rijzen.

Een nadere beschouwing van een aantal argumenten welke ten gunste van de persoonlijke tekening zouden kunnen worden aangevoerd sterkt schrijver in de overtuiging dat ondertekening uitsluitend met de maatschapsnaam, de voorkeur verdient.

A II-4

E $635.451:$ E 741.23

Maandblad voor accountancy en bedrijfshuishoudkunde, februari 1961

\section{ADMINISTRATIEVE ORGANISATIE}

\section{De systeemanalyse}

Berkel, I r P. L. M. va n - De automatisering van de administratic maakt dat het administratieve gebeuren opnieuw bezien zal moeten worden en in een geheel nieuw systeem samengebracht. De vastlegging van het huidige bedrijfsgebeuren is echter geenszins het belangrijkste onderwerp van de systeemanalyse. Deze dient te geschieden tegen een uitgebreide achtergrond van kennis van de mogelijkheden van elektronische administratie en het onderzoek zal steeds gericht zijn op de automatiseringsaspecten. De taak van de systeemanalyst is dan ook zeer uitgebreid en omvat o.a. een onderzoek naar de mogelijkheid van machinale verwerking der numerieke gegevens, naar die van het combineren van tabellen en van andere registraties, naar het verdere gebruik van alle gegevens welke het administratieve systeem binnenkomen, terwijl voorts het interview van groot belang is. Nadat de systeemanalysten hun gegevens bij elkaar gebracht hebben, wordt onder leiding van een deskundig systeemontwerper een ,ideaal" geautomatiseerd systeem geconstrueerd. De keuze van de zg. ,invoer" vormt hierbij een van de moeilijkste problemen. Naarmate de machines sneller werken en de geheugens groter worden, behoeven minder strenge eisen aan de hoedanigheid van de invoer te worden gesteld. Bij het doen van de machinekeuze zal men een compromis moeten aanvaarden, waardoor het systeem enige wijziging zal moeten ondergaan. Immers, geen fabriek levert de „ideale” machine.

A III-3 Maandblad voor Bedrijfsadministratie en -organisatie, februari 1961

E 738.4

m a b blz. 243 


\section{LEER VAN DE CONTROLE}

\section{Discovery Sampling in Auditing}

A rk in, H. - Bij het accountantsonderzoek wordt, als de contrôle betrekking heeft op een groot aantal gevallen, indien van een steekproef gebruik wordt gemaakt slechts een min of meer beperkt aantal gevallen op hun juistheid getest. De accountant is daarbij in het algemeen geïnteresseerd in drie soorten onregelmatigheden $t$.w. fouten tengevolge van onoplettendheid, fouten welke wijzen op het nict doclmatig functioneren van het interncontrôlesysteem en onregelmatigheden welke wijzen op manipulaties of fraude. Het doel van de test is gewoonlijk de eerste twee soorten onregelmatigheden op te sporen. Voor bepaalde onjuistheden, waaronder fraude, kan de belangstelling van de accountant zijn gericht op het al dan niet voorkomen daarvan. Een belangrijk probleem in dit verband waaraan de laatste tiid aandacht is besteed is het vaststellen van de grootte van de steekproef. Voor de toevallige steekproef is het mogelijk de waarschijnlijkheid te berekenen dat tenminste één foutief geval in de steekproef voorkome, gegeven totaal aantal gevallen en aantal foutieve gevallen. Er bestaan tabellen waaruit deze waarschijnlijkheid is af te lezen. Deze kunnen eveneens worden gebruikt om er indien in de steekproef geen foutief geval wordt aangetroffen de waarschijnlijkheid uit af te lezen dat het in het universum voorkomende aantal foutieve gevallen minder is dan werd verondersteld. De accountant zal moeten beslissen wat hij als redeiijke zekerheid beschouwt. Hij kan zijn zekerheid zo groor maken als hij wil maar dient wel te beseffen dat hoe hoger de verlangde zekerheid des te groter de steekproef moet zijn en dus des te hoger de kosten zullen worden.

A IV - 3

The Journal of Accountancy, februari 1961

E $635.451:$ E $741.23:$ E 76

\section{B. BEDRIJFSHUISHOUDKUNDE}

\section{a. ALGEMENE BEDRIJFSHUISHOUDKUNDE III. WAARNEMINGSMIDDELEN}

\section{Kan normaal leesbaar schrift al mechanisch worden gelezen?}

Het is nog niet mogelijk om voor de mens normaal leesbaar schrift mechanisch te lezen. Het blijkt voor een machine zelfs moeilijk te zijn om getypt schrift te lezen. Alleen gestileerd schrift kan vrij vlot mechanisch worden afgelezen, maar dan is men niet meer ver af van dubbelgecodeerde symbolen, waarvan één codeteken voor de mens en een ander voor de computor leesbaar is. Sommige firma's, onder andere E. M. J., Bull, Reumhelm en Cummins zijn erin geslaagd de machinetaal zodanig in het normale schrift in te brengen, dat men bij het lezen de aanwezigheid van de machine-code nauwelijks bemerkt.

Er zijn twee soorten van leestechniek: optisch lezen en magnetisch lezen. De storingskans door vlekken op het papier is bij magnetisch lezen, waarbij van inkt met magnetische eigenschappen gebruikt wordt gemaakt, praktisch nihil. Optisch lezen daarentegen is minder kostbaar, en is de laatste tijd aanzienlijk geperfectioneerd. De American Bankers Association gebruikt voor het lezen van cheques de magnetische leesmerhode. De optische methode is in gebruik bij de American Telephone and Telegraph Cy., de National Biscuit Cy., the Reader's Digest en de Standard Oil of California.

Ba III - 1 Informatie van de Stichting Studiecentrum voor Administratieve Automatisering, E 738.4

februari 1961

\section{The value of interfirm comparison}

In g h a m, H. - Geen twee ondernemingen zijn werkelijk gelijk. Toch is bedrijfsvergelijkende statistiek niet zinloos, want het gaat niet om de vergelijking van identieke ondernemingen, maar om te onderzoeken welke gevolgen verschillen in structuur hebben voor grootheden als winsten, kosten, afzet, arbeidsproductiviteit, enz. Het enige dat van belang is, is dat de ondernemingen voldoende overeenkomst vertonen om de vergelijking zinvol te doen zijn. Dit laatste zal van geval tot geval moeten worden bekeken.

Bedrijfsvergelijking bevordert meer dan welk ander middel de efficiency in het bedrijf doordat objectief wordt aangetoond wat de zwakke punten zijn. Een ander voordeel van bedrijfsvergelijking is, dat de gemiddelde efficiëntie van de bedrijfstak stijgt.

Ba III - 2

The Manager, februari 1961

E 76

\section{Bestelniveau en serie-grootte}

H e e s, I r R. N. van - De optimale serie-grootte komt alleen in het z.g. B.Q.systeem op ongeschonden wijze naar voren. In dit systeem wordt gewerkt met een beste:- 
niveau (B) en een serie-grootte (Q). De klassieke formule voor het berekenen van de opt1male serie-grootte gaat ervan uit, dat er met voorraad wordt gewerkt, welke stootsgewijs wordt aangevuld op bekende tijdstippen en waaruit min of meer regelmatig wordt afafgenomen, terwijl de afgeleverde hoeveelheden gemiddeld kleiner zijn dan de helft van de aanvullingsorders. Wordt besloten het B.Q.-systeem toe te passen dan zal de bepaling van de juiste bestelniveaus een belangrijk deel van de berekening vormen. Het artikel is geheel gewijd aan de bepaling van het bestelniveau. Ter sprake komt allereerst het pre-advies van Dr A. M. Groot voor de Najaars-Efficiencydagen 1959. De tabel, die Dr Groot opstelt is volgens Ir van Hees gebaseerd op vereenvoudigende veronderstellingen, waaraan in de werkelijkheid zelden zal zijn voldaan. Het gebruik van deze tabel bij de berekening van het bestelniveau zal dus in het algemeen tot volkomen verkeerde resultaten leiden. Vervolgens bespreekt de auteur de verwachting van de gemiddelde vraag, de spreiding in de vraag, de levertijd en de frequentieverdeling van de vraag. In afwijking van Groot neemt van Hees aan dat het aantal orders per tijdseenheid geen Poisson- of normale verdeling, maar een gamma-verdeling vertoont. Accepteert men dit uitgangspunt dan kan met behulp van de tabel, die aan het artikel is toegevoegd op zeer eenvoudige wijze het bestelniveau bepaald worden.

Ba III - 2

Tijdschrift voor Efficiëntie en Documentatie, februari 1961

E 76

\section{LEER VAN DE KOSTPRIJS EN PRIJSVORMING}

\section{Accounting for Price Level Changes}

Het Canadian Institute of Chartered Accountants wijdde haar laatste jaarlijkse congres aan het probleem van de waarderegistratie in tijden van fluctuerende prijzen.

Daar accountantsverklaringen meestal bestemd zijn om door niet-accountants gelezen te worden, dient de accountant zich in zijn terminologie aan te passen aan zijn lezers. Als "men" onder inkomen verstaat het bedrag, dat aan het bedrijf onttrokken kan worden, zonder dat daardoor de beschikkingsmacht over goederen en diensten wordt aangetast, kan de accountant nict vasthouden aan de conventionele definitie van verschil tussen inkomsten en uitgaven, temeer omdat deze definitie berust op een irreële veronderstelling, $\mathrm{nl}$. constante koopkracht van het geld, of althans een geldswaarde, die fluctueert om een constante waarde. Zodra een inflatie van enige omvang optreedt gaat deze veronderstelling niet meer op; verklaringen daarop gegrond verliezen gedeeltelijk of geheel hun waarde als objectief oordeel over de bedrijfsgang. De bezwaren, veelal door tegenstanders van cen aanpassing aan prijswijzigingen naar voren gebracht, van verminderde objectiviteit der waardebepaling en mogelijke verwarring doordat naast elkaar verschillende waarderingsmaatstaven gebruikt worden, kunnen worden opgevangen door gebruik te maken van een prijsindexcijfer, en de op grond hiervan berekende correcties als aanvullende informatie naast de conventioneel berekende gegevens te verschaffen.

Teneinde de objektiviteit te verzekeren kan men het best gebruik maken van een zo algemeen mogelijk indexcijfer, dat geen invloed ondergaat van wijzigingen in de marktverhoudingen in een bepaalde sector, of van fluctuaties in de algemene economische bedrijvigheid. Het indexcijfer voor het gezinsverbruik zou hier vrij redelijk aan voldoen; eventueel zou men een speciaal indexcijfer kunnen berekenen op basis van het totale bruto nationaal produkt. Voor de vervangingswaarde als maatstaf voor waardeveranderingen geldt het bezwaar, dat men dan beslist speciale marktinvloeden opneemt; tevens, als men de vervangingswaarde ziet als het bedrag, waartegen t.z.t. de vervanging zal plaatsvinden, hoezeer dit ook uit financieringsoverwegingen opportuun zou zijn, brengt men daarmee een uitermate speculatief element in de berekeningen, waarvan het op zijn minst twijfelachtig is, of het een bepalende factor mag zijn bij de bepaling van het inkomen.

$\mathrm{Ba}$ IV - $2 \mathrm{e}$

The Canadian Chartered Accountant, januari 1961

E 136.322.1

\section{Toepassing van substantialistische winstopvattingen op het fiscale terrein}

$\mathrm{M}$ u is w in ke l, Prof. D r. F. L. va n-De commissie-Tinbergen heeft aan de Vereniging voor Belastingwetenschap een rapport uitgebracht over de mogelijkheden tot fiscaalrechtelijke toepassing van een substantialistische winstopvatting. Aan de hand van een samenvatting van het rapport plaatst de schrijver enige bedrijfseconomische kanttekeningen. De voorgestelde, voor de fiscus aanvaardbare en praktisch toepasbare methode omvat toepassing van het ijzeren- of normale-voorraadstelsel voor de zgn. deelbare voorraden en jaarlijkse afschrijvingen op basis van uitgaafprijs gecorrigeerd met bindende prijsindexcijfers voor de duurzame activa.

De schrijver acht het een ernstig gemis, dat de commissie geen principiële voorkeur aangeeft op het punt van het begrip ijzeren voorraad en het bepalen van de omvang ervan, 
doch slechts de in de literatuur bekende mogelijkheden opsomt. De door de commissie gehanteerde beginselen wijzen volgens de auteur in de richting van een economische voorraad met inbegrip van geplaatste bestellingen. Andere kritische opmerkingen betreffen o.m. het feit dat de commissie ,ter wille van de eenvoud" in enkele nadelen van het systeem van indexatie berust. Met name voorziet dit systeem niet in de bij prijsstijging ter wille van de continuïteit noodzakelijke , inhaalafschrijvingen" op reeds verbruikte werkcenheden; zowel bij het ijzeren-voorraadstelsel als bij de vervangingswaardeleer komen deze inhaalafschrijvingen automatisch tot stand.

Hoewel de schrijver voor de door de commissie gevolgde weg van de praktische oplossingen positieve waardering heeft, acht hij het nochtans dringend noodzakelijk voort te gaan op de wetenschappelijke weg; de door de commissie verdedigde of verworpen methoden en technieken behoeven een wetenschappelijk verantwoord fundament terwijl gepoogd moet worden de fiscus door een wetenschappelijk betoog tot een juist bedrijfseconomisch inzicht te brengen.

$\mathrm{Ba}$ IV - 7

De Naamlooze Vennootschap, febrwari 1961

E 136.322 .1 : E 332.423

\section{Belasting en vervangingswaarden uit nationaal oogpunt gezien}

't $\mathrm{H}$ o of t-W e I va ars, M. J. - Naar aanleiding van het vijfde hoofdstuk van het rapport van de commissie-Tinbergen, waarin een aantal bezwaren tegen tocpassing van substantialistische beginselen bij de fiscale winstbepaling wordt onderzocht, geeft de schrijfster enkele macro-economische beschouwingen. Achtereenvolgens worden behandeld de gevolgen van de overgang van het nominalistische naar een substantialistisch fiscaal winstbegrip in verband met de geleidelijke inflatie, de conjuncturele prijsveranderingen en de verandering in de relatieve prijzen der produktiemiddelen. De invoering van een nieuw fiscaal winstbegrip neemt de huidige onrechtvaardige verdeling van de belastingdruk weg maar doet tevens de belastingopbrengst afnemen naarmate de inflatoire prijsstijging sterker is. Dit laatste zou gecompenseerd kunnen worden door een verhoging van de belastingtarieven terwijl faciliteiten als investeringsaftrek en vervroegde afschrijving zouden moeten worden opgeheven. De noodzaak schijnt aanwezig dat invoering van een substantialistisch winstbegrip gepaard gaat met variabele tarieven, en wel variërend met de jaarlijkse niet-incidentele stijging of daling van het algemeen prijsniveau. Op deze wijze zou een automatisch middel tot conjunctuurbestrijding, tot matiging van de hausse vooral, gehandhaafd kunnen worden. Ten aanzien van relatieve prijsveranderingen vraagt de schrijfster zich af of de overheid zich wel zal aansluiten bij tweeërlei interpretatie door de commissie van een nieuw winstbegrip, nl. gebaseerd of op de specifieke prijsstijging van een groep gelijksoortige produktiemiddelen of op de algemene geldontwaarding, die zo gekozen is dat de belastingopbrengst altijd zo gering mogelijk wordt.

$\mathrm{Ba}$ IV -7

E 136.322 .1 : E 332.423

\section{Die Stellung der Gewinnsteuern in Kostentheorie und Kostenrechnung}

Schweizer, P. - De vraag of belastingen tot de kostenfaktoren behoren is in beginsel een kwestie van terminologie en doelmatigheid. Het in de theoretische economie gehanteerde kosten- en winstbegrip en de daaruit volgende opvatting dat winstbelastingen geen kosten zijn, acht de schrijver niet bruikbaar voor de praktijk. Uit het gangbare nominalistische winstbegrip, waarvan ook het fiscale is afgeleid, volgt als ondernemerswinst het saldo van opbrengsten en uitgaven dat ter beschikking komt van de drager van de ondernemersfunctie. Een deel van deze winst dient tot dekking van de kosten zodat de over dit deel geheven belasting oorzakelijk verbonden is met de bedrijfsverrichtingen en tot kostenfaktor wordt. De schrijver meent dat alleen dan sprake is van schijnwinsten en de belastingen daarover een kostenkarakter dragen indien de oorzaak is gelegen in een algemene stijging van het prijsniveau. Reserveringen ten gevolge van specifieke prijsstijgingen in de afzonderlijke onderneming of bedrijfstak, van hoe grote betekenis ook, zijn geen schijnwinsten hetgeen zou blijken bij liquidatie: de ingehouden winst vloeit dan als additionele koopkracht aan de ondernemer toe.

Eén van de elcmentaire functies van de kostprijsberekening, in verband met de alternatieve aanwendingsmogelijkheden van arbeid en kapitaal, is het bepalen van die minimumprijzen waarbij op lange termijn nog juist alle kosten worden gedekt. Opdat in deze kosten ook wordt opgenomen het bedrag aan winstbelastingen dat op lange termijn door de voortbrenging wordt veroorzakkt, dient het belastingtarief te worden toegepast op de in de fiscale winst begrepen kostenfaktoren. Door af te zien van de feitelijk betaalde belastingbedragen verkrijgt men op dezc wijze een kostenberekening die het mogelijk maakt de prijspolitiek op lange termijn te beoordelen.

$\mathrm{Ba}$ IV -7

E 332.423

Die Wirtschaftsprïfung, februari 1961

m a b blz. 246 


\section{LEER VAN DE FINANCIERING}

\section{Small business financing}

Het in het mei-repertorium aangekondigde artikel over de enquête onder de ondernemingen, die niet in de vorm van een naamloze vennootschap worden gedreven is nog niet in het Federal Reserve Bulletin verschenen. Zodra het artikel verschijnt zal daarvan in het repertorium een overzicht worden gegeven.

$\mathrm{Ba} \mathrm{V}-3 \mathrm{a}$

E 325.0

\section{LEER VAN DE ORGANISATIE}

\section{Wat is administratie? Heroriëntering omtrent een begripsbepaling}

Starreveld, Prof. R. W. - In dit artikel wordt de in de toelichting van het nieuwe studieprogramma van het N.I.v.A. voor het vak Administratieve Organisatie gegeven omschrijving van het begrip administreren nader gemotiveerd. Uitgaande van de globale karakteristiek van het speciale gebied van onderzoek - systematische vastlegging en verwerking van informatie met betrekking tot een huishouding - wordt het gebied begrensd met als voornaamste criterium het optreden van dezelfde informatie-elementen. Dit criterium concentreert de aandacht in het bijzonder op de informatie die nodig is voor het besturen en doen functioneren van een huishouding alsmede van het afleggen van verantwoording over het gebruik van gedelegeerde bevoegdheden. Deze toespitsing van de aandacht vindt o.m. zijn motivering in: (1) de innerlijke samenhang tussen besturen, doen functioneren en verantwoorden, doordat deze in beginsel op dezelfde objecten en handelingen betrekking hebben, (2) de omstandigheid dat de basis-informatie ten behoeve van de oordeelsvorming welke aan het nemen der beslissingen voorafgaat grotendeels aan ten behoeve van de contrôle samengestelde overzichten kan worden ontleend, (3) de relatie tussen de basis-informatie en de daarop gebaseerde beslissingsprocessen, (4) het verband tussen beslissing, opdrachtgeving en uitvoeringsvoorbereiding, (5) de samenhang tussen opdracht, primaire verantwoording en doorberekening van kosten en opbrengsten, (6) de mogelijkheden tot contrôle op de juistheid van de informatie door onderlinge vergelijking van gegevens ontleend aan verschillende onderdelen van de administratie.

Het aanbrengen van een beperking in de begripsbepaling die de numerieke informatie op de voorgrond stelt heeft weinig zin. Op grond van de vermelde overwegingen wordt administreren omschreven als: ,het systematisch verzamelen, vastleggen, verwerken en verstrekken van informatie ten behoeve van het besturen en doen functioneren van een huishouding, en ten behoeve van de verantwoording die daarover moet worden afgelegd". Ba VI - 13 Maandblad voor accountancy en bedrijfshuishoudkunde, februari 1960 E 741.2

\section{Werkmeister und betriebliche Entwicklung}

Het januari-nummer van Industrielle Organisation is geheel gewijd aan de problematiek rond de werkbaas.

Walter Vogel opent het nummer met een schets van de positie van de werkbaas in het bedrijf. W. F. Daenzer stelt in "Zum Berufsbild des Werkmeisters" dat tegenwoordig steeds meer functies van de werkbaas op andere organen worden overgeheveld, maar dat dit de wezenlijke functie van de werkbaas - nl. de schakel tussen planning en uitvoering te zijn niet aantast. Nauw hierbij sluiten aan het artikel van Hans Hofer, getiteld „Der Werkmeister im Spannungsfeld der betrieblichen Zusammenarbeit" en dat van Gottfried Straub over „Die zukünftige Bedeutung des Werkmeisters für die Unternehmung”.

In de volgende artikelen wordt de opleiding en de scholing besproken: Hans Etter „Der Beitrag des Werkmeisters zur betrieblichen Entwicklung”, Robert Rüttener ,Perspektiven der zukünftigen Werkmeisterausbildung”, Willy Sulzberger „Werkmeister und betriebliche Entwicklung”, Hans Herrli „Kader-Ausbildung im Baugewerbe”, Marcel Flück „Meisterausbildung in der Textilindustrie".

$\mathrm{Ba}$ VI - 13

E 642.431

Industrielle Organisation 1961, nr. 1

\section{Die Planungsrechnung im modernen Betrieb}

Ill e $\mathrm{s} s \mathrm{chk}$ o, Prof. D r. L. L. - De schrijver stelt dat de bedrijfsbegroting in concreto een zodanige gebondenheid van de financiële middelen in investeringen dient te kunnen vaststellen dat in de toekomst het financiële evenwicht van het bedrijf niet verloren gaat. Hoewel de historisch georiënteerde boekhouding en de kostprijscalculatie in dit opzicht te kort schieten, kunnen beide onderdelen van de bedrijfsadministratie niet gemist 
worden. Het gestelde doel van de handhaving van het financiële evenwicht eist de gelijktijdige bewaking en prognose van de inkomsten en uitgaven. De bedrijfsbegroting is een afzonderlijk en zelfstandig onderdeel naast de jaarrekening en de kostprijsberekening, doch tezamen vormen zij een drie-eenheid; de andere twee worden in opzet en beloop beinvloed door de doelstellingen van de begroting. De begroting moet bestaan uit twee onderdelen, het ene betrekking hebbend op kosten, in fiscale zin, en opbrengsten, waaruit de vermogensmutatie voortvloeit, het andere de te verwachten vermogens- en investeringspositie weergevend; hieruit blijkt of en in hoeverre het financieel evenwicht behouden blijft bij de geprojecteerde produktie en afzet. Deze door de schrijver in een voorbeeld voor een periode van vijf jaar geschetste begrotingsopstelling is naar zijn mening ook toe te passen bij middel-grote en kleine bedrijven.

Ba VI - 18

Wirtschaftlichkeit, $1 / 21960$

E 641.231 .3

\section{LEER VAN DE ARBEIDSVOORWAARDEN}

\section{Wetgeving, regering, vakbeweging}

Ven, Prof. Mr J. J. M. van de $\mathrm{r}$ - Tot de belangwekkendste verschijnselen in het maatschappelijke leven van Nederland behoort de vakbeweging. Des te verwonderlijker is het, dat de vakcentrales en vakbonden nauwelijks een eigen juridisch gezicht vertonen, zij verdwijnen in de grauwe massa van "verenigingen”, koninklijk goedgekeurd volgens één van onze oudste nog dagelijks vigerende wetten, de wet van 22 april 1855, stammend uit een tijd waarin vakbonden nog aan geen enkele vaderlandse horizon te bespeuren warcn. In de Verenigde Staten daarentegen bestaat een omvangrijke wettelijke regeling van de vakbeweging. De jongste wet op dit gebied is de „Labor Management and Disclosure Act" van 1959. Deze wet beoogt de interne democratie te bevorderen en wangedrag in het optreden naar buiten tegen te gaan.

Wat betreft de interne democratie is één van de belangrijkste punten, dat alle tekortkomingen van een vakbond jegens éen van zijn leden met betrekking tot het stellen van kandidaten voor bestuursfuncties, het deelnemen aan verkiezingen, het bijwonen van ledenvergaderingen, verhoging van financiële verplichtingen, beperking van de rechten der leden om processen te voeren of als getuige op te treden, dit lid aanleiding mogen geven tot civielrechtelijke actie. Een ander belangrijk punt is de plicht tot mededeling aan de Secretary of Labor van tal van zaken, waaronder alle financiële transacties tussen bondsleden en ondernemers, voorzover zij, al is het maar middellijk, de gestes van de bond of de leden kunnen raken.

De Secretary of Labor is met uitgebreide bevoegdheden bekleed om allerlei onoirbare gewelddadigheden, waaronder in het biizonder het uitoefenen van afpersingsdruk door middel van posten, tegen te gaan.

Tot slot behandelt de schrijver de vraag in hoeverre ook in Nederland behoefte aan een dergelijke regeling bestaat. De auteur beantwoordt deze vraag in het algemeen ontkennend, maar maakt een uitzondering met betrekking tot het geheimhouden van de geldbronnen achter de bondskassen. Het onthullen van geheime geldbronnen achter de bondskassen zou immers menigeen van verdere deelneming aan een staking kunnen afschrikken.

\section{Rondom de Bedrijfsbond}

Orme l, D. W. - In dit artikel wordt een beschouwing gegeven over de huidige stand van de vorming van bedrijfsbonden in de Nederlandse arbeidersvakbeweging.

$\mathrm{Bij}$ het streven de beroepsgewijze organisatievorm te vervangen door de bedrijfstaksgewijze, blijkt men op velerlei moeilijkheden te stuiten. Hierbij is die van de herverdeling van de georganiseerden tussen de verschillende vakorganisaties, van primaire betekenis. De bereidheid tot medewerking aan de instelling van de bedrijfsbonden is niet in alle vakcentrales gelijkelijk aanwezig. Vooral bij de beambtenorganisaties stuitte men op verzet: de beambten wensten vast te houden aan de eigen status of waren de mening toegedaan dat het om principiële redenen niet was geoorloofd beambten en handarbeiders in én organisatie te verenigen. Een en ander heeft ertoe geleid dat men van bepaalde zijde zich opnieuw is gaan beraden over de wenselijkheid van de bedrijfstaksgewijze organisatie. De schrijver legt grote nadruk op het belang van een goede verstandhouding en samenwerking tussen de beambten en de uitvoerende werknemers.

Ba VII - 4 Gids voor Personeelsbeleid, Arbeidsvraagstukken, Sociale Verzekering, E 224.321 februari 1961 